\title{
Pengaruh Pendapatan Berbasis Biaya Pada Return of Asset (ROA) pada Bank Bank di Indonesia
}

\author{
Arief Fadholi \\ Universitas Bina Sarana Informatika \\ e-mail: arief.ahl@bsi.ac.id
}

\begin{abstract}
The objective of this research is to examine the effect of fee based income on return on assets of listed banks in Indonesia stock exchange during 2006-2010. Three types of fee based income are investigated, namely income from provisions and commissions, income from foreign exchange transaction services, and income from other bank services. In addition, total asset is also included in the model as one of the independent variable. A sample of 24 banks is used in this study. A multiple regression based on the ordinary least squared $(O L S)$. The result shows that the three types of fee based income have a positive and significant effect on return on assets. However, total assets do not have a significant effect. Overall, the result suggests that banks should promote their fee based income activities in order to increase their profitability.
\end{abstract}

Key Word: Fee Based Income, Return of Asset

\section{PENDAHULUAN}

Bank merupakan lembaga yang memegang peranan penting dalam perekonomian suatu negara. Kemajuan bank di suatu negara dapat dijadikan tolak ukur kemajuan negara tersebut, khususnya peran perbankan sebagai penyedia pembiayaan industri dalam negeri. Pentingnya peranan perbankan dalam kegiatan perekonomian tersebut dapat dilihat dari definisi bank dalam Undang-undang Nomor 10 tahun 1998 sebagai berikut: Bank adalah badan usaha yang menghimpun dana dari masyarakat dalam bentuk simpanan dan menyalurkannya kepada masyarakat dalam bentuk kredit dan atau bentukbentuk lainnya dalam rangka meningkatkan taraf hidup rakyat banyak.

Untuk mewujudkan peranan penting tersebut perbankan dituntut bekerja seefektif dan seefisien mungkin agar dapat menjaga kelangsungan usahanya. Sebagai lembaga yang bersifat profit oriented atau bertujuan memperoleh laba maka perbankan perlu sangat berhati-hati (prudent) dalam menjalankan aktivitas usahanya, terutama karena bank bekerja dengan dana yang diperoleh dari masyarakat yang dititipkan padanya atas dasar kepercayaan.

Laba yang diperoleh bank akan memberikan jaminan pada bank itu sendiri untuk tumbuh dan berkembang guna mengantisipasi perkembangan pasar yang ada, serta eksis dalam menghadapi persaingan antar bank. Kemampuan bank untuk menghasilkan laba selama periode tertentu yang dinyatakan dalam persentase $(\%)$ disebut dengan profitabilitas (S. Munawir, 2004).

Profitabilitas menjadi salah satu indikator kinerja keuangan bank. Apabila bank mengalami rugi usaha, maka hal itu akan menghambat kegiatan operasional dan berdampak pada tingkat kesehatannya. Jika terjadi penurunan laba secara terus menerus dalam jangka waktu yang panjang akan memungkinkan bank mengalami kebangkrutan dikarenakan tidak mampu memenuhi biaya operasionalnya.

Untuk meningkatkan jumlah laba yang diperoleh, bank harus meningkatkan pendapatan dan menekan biaya-biaya agar lebih efisien. Pendapatan yang diperoleh bank akan berpeluang meningkatkan perolehan laba dan akan mempengaruhi besarnya profitabilitas yang dicapai suatu bank.

Jenis pendapatan yang di peroleh bank atas produk dan jasa yang diberikan kepada masyarakat menurut (Kasmir, 2002) dapat dibagi menjadi dua golongan yaitu Interest Income dan Fee Based Income. Secara singkat, interest income adalah pendapatan yang diperoleh dalam bentuk bunga atas pemberian kredit sebagai penyalur kepada masyarakat, baik perorangan atau badan usaha dan juga penempatan dana kepada bank lain. Sedangkan Fee Based Income adalah pendapatan provisi, fee atau komisi yang diperoleh bank yang bukan merupakan pendapatan bunga. Dengan semakin ketatnya persaingan di dalam industri perbankan dan persaingan dengan lembaga keuangan bukan bank dewasa ini, maka bank dituntut untuk mencari sumber pendapatan baru diluar penghasilan bunga dari kredit, khususnya dari fee based income. Secara umum, fee based income tergantung pada proses marketing mix management (product, price, promotion). Dengan semakin banyaknya produk dan jasa yang ditawarkan bank, maka semakin banyak peluang untuk mendapatkan keuntungan dari fee based income. Berdasarkan analisa diatas maka 
dalam penelitian ini akan dilakukan penelitian mengenai pengaruh dari fee based income terhadap pendapat bank

\section{METODOLOGI PENELITIAN}

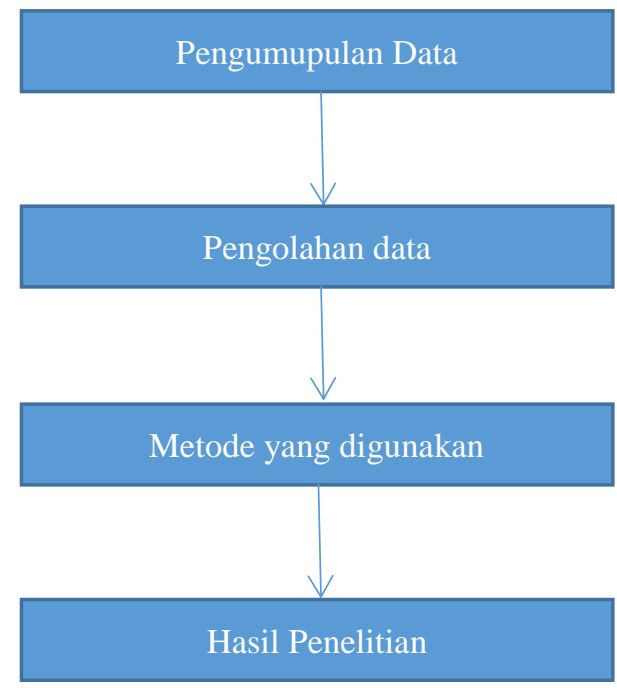

Sumber: Penulis

Gambar 1 Tahapan Penelitian

\subsection{Pengumpulan Data}

Penelitian ini menggunakan data sekunder bersumber dari laporan keuangan tahunan yang didapatkan dari Neraca dan Rugi/Laba yang telah dipublikasikan atau kumpulan rasio-rasio keuangan perbankan yang diikuti secara time series selama 5 tahun (2006-2010) dan cross section terhadap semua sampel penelitian. Dengan demikian data yang akan diolah bersifat pooled data.

HData yang diperlukan dalam penelitian ini, meliputi: (1).Return on Asset, yaitu laba bersih sebagai persentase dari total asset, (2).Pendapatan provisi dan komisi, dihitung sebagai persentase dari total asset, (3).Pendapatan transaksi valuta asing, dihitung sebagai persentase dari total asset, (4).Pendapatan jasa perbankan lainnya, dihitung sebagai persentase dari total asset, (5).Total asset, yaitu posisi total asset bank pada setiap akhir tahun selama periode penelitian.

\subsection{Pengolahan Data}

Penelitian ini menggunakan satu variabel terikat $(\mathrm{Y})$ yaitu, Return on Assets (ROA) dan empat variabel bebas (X) yaitu, Pendapatan provisi dan komisi, pendapatan transaksi valuta asing, pendapatan jasa perbankan lainnya, serta total asset.

\subsection{Definisi Operasional Variabel}

Adapun definisi operasional dari masing-masing variabel dependen dan independen di atas adalah sebagai berikut :

1. Variabel pendapatan provisi dan komisi (X1) adalah pendapatan yang diperoleh dari hasil provisi dan komisi dari pelayanan nasabah setiap akhir tahun selama 5 tahun penelitian (2006-2010).

2. Variabel pendapatan valas (X2) adalah pendapatan yang diperoleh dari hasil jual beli valas dari layanan nasabah setiap akhir tahun selama 5 tahun penelitian (2006-2010).

3. Variabel pendapatan jasa perbankan lainnya (X3) adalah pendapatan yang diperoleh dari hasil pemberian jasa layanan nasabah setiap akhir tahun selama 5 tahun penelitian (20062010).

4. Variabel total asset (X4) adalah posisi total asset bank pada setiap akhir tahun selama 5 tahun penelitian (2006-2010).

5. Variabel (ROA) (Y) merupakan dependen variable, yaitu posisi ROA setiap akhir tahun selama 5 tahun terakhir (2006-2010).

\subsection{Model Penelitian}

\section{Variable X}

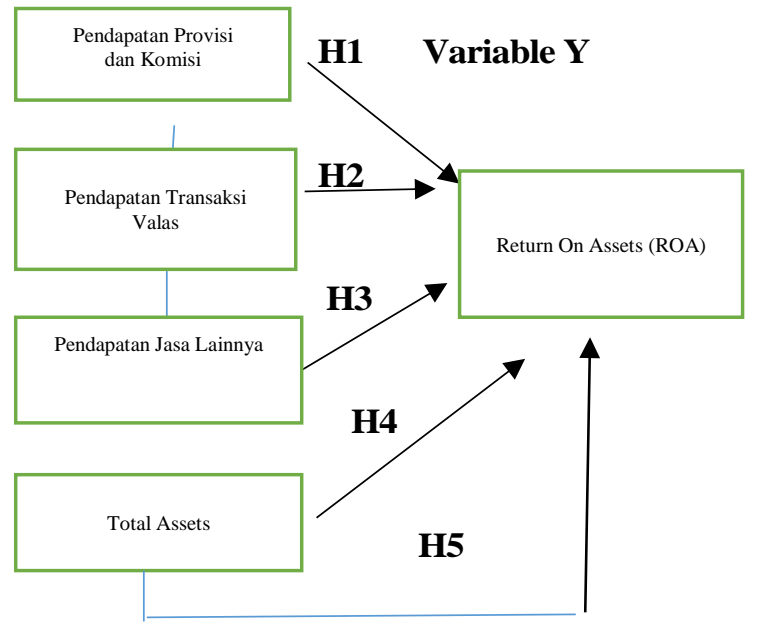

Sumber : Penulis

Gambar 2. Model Penelitian

Hipotesis yang akan diuji dalam penelitian ini adalah sebagai berikut:

H1: Pendapatan provisi dan komisi berpengaruh signifikan terhadap ROA Bank-Bank yang terdaftar di Bursa Efek Indonesia 2006-2010

H2: Pendapatan valuta asing berpengaruh signifikan terhadap ROA Bank-Bank yang terdaftar di Bursa Efek Indonesia 2006-2010 
H3: Pendapatan jasa perbankan lainnya berpengaruh signifikan terhadap ROA Bank-Bank yang terdaftar di Bursa Efek Indonesia 2006-2010

H4: Total Asset berpengaruh signifikan terhadap ROA Bank-Bank yang terdaftar di Bursa Efek Indonesia 2006-2010

H5: Secara bersama-sama (simultan), pendapatan provisi dan komisi, pendapatan transaksi valuta asing, pendapatan jasa bank lainnya dan total asset berpengaruh signifikan terhadap ROA BankBank yang terdaftar di Bursa Efek Indonesia tahun 2006-2010.

Metode penelitian yang digunakan untuk penelitian ini adalah metode deskripti, yaitu metode yang bertujuan untuk menggambarkan sesuatu yang tengah berlangsung pada saat riset tengah dilakukan dan memeriksa sebab akibat dari suatu gejala tertentu.

Metode deskriptif sendiri dapat dipilah-pilah lebih spesifik lagi menjadi tujuh jenis penelitian yaitu, studi kasus, survey, riset pengembangan, riset lanjutan, riset dokumen, riset kecenderungan, dan riset korelasi.

Penelitian ini tergolong riset korelasi, yaitu penelitian yang dirancang untuk menentukan tingkat hubungan variabel-variabel yang berbeda dalam suatu populasi. Melalui riset korelasi ini dapat diketahui seberapa besar kontribusi variabel-variabel bebas terhadap variabel terikat dan besarnya arah hubungan yang terjadi (Umar, 2005).

\section{HASIL DAN PEMBAHASAN}

Statistik deskriptif dari variabel-variabel yang digunakan dalam penelitian ini akan dibahas dalam bab ini. Penelitian ini menggunakan satu variabel terikat (Y) yaitu Return on Assets (ROA), dan empat variabel bebas (X) yaitu, Pendapatan Provisi dan Komisi (disingkat PROVKOM), pendapatan transaksi valuta asing (disingkat TRANSVAL), pendapatan jasa perbankan lainnya (disingkat JASALAIN), serta total asset (disingkat TA). Statistik deskriptif dari variabel-variabel tersebut dapat dilihat pada tabel berikut ini:

Tabel 1 Statistik Deskriptif - Data Mentah

\begin{tabular}{|c|c|c|c|c|c|c|c|}
\hline \multicolumn{8}{|c|}{ Descriptive Statistics } \\
\hline & N & Minimum & Maximum & Mean & Std. Deviation & & wness \\
\hline & Statistic & Statistic & Staisicic & Statistic & Statisic & Statistic & Sto. Error \\
\hline $\mathrm{ROA}$ & 120 & .86 & 1.68 & .3353 & .34788 & .918 & 221 \\
\hline PROMOM & 120 & & $4.97328 \mathrm{E} 1$ & 1.1254186E1 & 1.07939906E 1 & 1.082 & 221 \\
\hline TRANSVAL & 120 & $-4.099 E-2$ & $1.80647 \mathrm{E} 1$ & $2.9401567 \mathrm{EO}$ & $3.52895502 E 0$ & 1.783 & .221 \\
\hline JASALAN & 120 & 1.2005E-1 & 1.20641E2 & 1.4234721E1 & $1.64485024 E 1$ & 3.214 & 221 \\
\hline TA & 120 & 16980 & 16121613 & 2693853.67 & 3654043.442 & 1.787 & 221 \\
\hline Valid N(Iistwise) & 120 & & & & & & \\
\hline
\end{tabular}

Berdasarkan Tabel 1 di atas, jumlah titik data dalam penelitian ini adalah 120 yang berasal dari 24 bank selama 5 tahun jangka waktu penelitian (20062010).

1. ROA memiliki nilai mean sebesar $0,33 \%$ dengan nilai minimum sebesar $-0,86 \%$ dan maksimum $1,68 \%$ sedangkan standar deviasinya sebesar $0,35 \%$. Adapun nilai skewnessnya sebesar 0,92 .

2. PROVKOM memiliki nilai mean sebesar $11,25 \%$ serta nilai minimum sebesar $0,03 \%$ dan nilai maksimum sebesar $49,73 \%$ sedangkan standar deviasinya sebesar $10,79 \%$. Nilai skewnessnya sebesar 1,08 .

3. TRANSVAL memiliki nilai mean sebesar $2,94 \%$ serta nilai minimum sebesar $-0,04 \%$ dan nilai maksimum sebesar $18,06 \%$ sedangkan standar deviasinya sebesar $3,53 \%$. Nilai skewnessnya sebesar 1,78 .

4. JASALAIN memiliki nilai mean sebesar $14,23 \%$ serta nilai minimum sebesar $0,13 \%$ dan nilai maksimum sebesar $120,64 \%$ sedangkan standar deviasinya sebesar $16,45 \%$. Nilai skewnessnya sebesar 3,21.

5. TA memiliki nilai mean sebesar Rp26,9 triliun serta nilai minimum sebesar Rp0,17 triliun dan nilai maksimum sebesar Rp161,21 triliun sedangkan standar deviasinya sebesar 36,54\%. Nilai skewnessnya sebesar 1,79.

\subsection{Analisis Hasil dan Interpretasi \\ 1. Pengujian Asumsi Klasik \\ a. Uji Normalitas}

Uji Normalitas dalam penelitian ini menggunakan nilai skewness. Skewnees adalah nilai kecondongan (kemiringan) suatu kurva yang cendrung seimbang. (Nugroho, 2005). Tabel 1 menunjukan bahwa ROA memiliki nilai skewness 0,92. Pendapatan Provisi dan Komisi (PROVKOM) memiliki nilai skewness 1,08\%, Pendapatan Transaksi Valuta Asing (TRANSVAL) memiliki skewness 1,78\%, Pendapatan Jasa Perbankan Lainnya (JASALAIN) memiliki skewness $3,21 \%$, dan total asset (TA) memiliki nilai skewness $1,78 \%$. Dengan demikian, secara umum hampIr seluruh variable bebas datanya cenderung kurang normal terbukti dari nilai skewness yang menjauhi 0 (nol). Oleh karena itu agar seluruh variable bebas menjadi normal dilakukan transformasi natural logaritma (LN), sehingga nilai skewness setelah transformasi sekarang menunjukkan distribusi data yang normal (lihat Tabel 2). 
Tabel 2 Statistik Deskriptif - Setelah

Transformasi LN

Descriptive Statistics

\begin{tabular}{|c|c|c|c|c|c|c|c|}
\hline & $\begin{array}{c}\text { N } \\
\text { Statisic }\end{array}$ & $\begin{array}{l}\text { Mrimum } \\
\text { Staisisic }\end{array}$ & $\begin{array}{l}\text { Maximum } \\
\text { Statisic }\end{array}$ & $\begin{array}{l}\text { Nean } \\
\text { Statisicic }\end{array}$ & $\begin{array}{l}\text { Sitid Deviaion } \\
\text { Statisicic }\end{array}$ & $\begin{array}{l}\text { Skew } \\
\text { Staisistic }\end{array}$ & $\begin{array}{l}\text { ness } \\
\text { Stht Error }\end{array}$ \\
\hline ROA & 120 & .86 & 1.68 & .3353 & 34788 & .918 & 221 \\
\hline LNPROMOM & 120 & $3.4200 E 0$ & 3.90666EO & $1.7143 E 0$ & $1.43810948 E 0$ & .740 & .221 \\
\hline LNTRASVIK & 120 & 4.7103EO & 2.89672EO & $\cdot 1.225 E-3$ & 1.87916870E0 & .567 & 221 \\
\hline LNJASALAN & 120 & $-20475 E 0$ & 4.79282EE & 200968EO & 1.16598729E0 & .604 & 221 \\
\hline LNTA & 120 & 9.7397:E0 & 1.65556E1 & $1.3578 \mathrm{E} 1$ & $1.83174342 E 0$ & 174 & .221 \\
\hline Valid N(Iistwise) & 120 & & & & & & \\
\hline
\end{tabular}

sumber : Data Primer Yang diolah (2006-2010)

\section{b. Uji Multikolinearitas}

Uji Multikolinearitas dilakukan dengan memperhatikan hasil perhitungan Tolerance dan Variance Inflation Factor (VIF) sebagaimana terlihat pada Tabel berikut ini:

\section{Tabel 3 Uji Multikolinearitas}

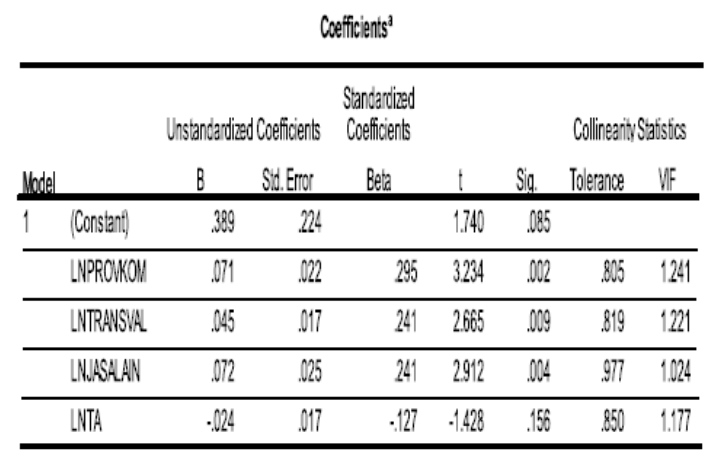

a. DepercicentVlarabe: ROA

sumber : Data Primer Yang diolah (2006-2010)

Tabel 3. menunjukkan tidak ada variabel bebas yang memiliki nilai Tolerance kurang dari 0,10 yang berarti tidak ada korelasi antara variabel independent yang nilainya lebih dari $95 \%$. Hasil perhitungan VIF juga menunjukkan hal yang sama karena tidak ada satupun variabel bebas yang memiliki VIF lebih dari 10. Jadi dapat disimpulkan bahwa tidak ada multikolinearitas diantara sesama variabel bebas dalam model regresi.

\section{c. Uji Heteroskesdastisitas}

Uji Heteroskesdastisitas dilakukan dengan memperhatikan hasil Scatterplot dan Uji White. Pada Gambar 3 Scatterplot memperlihatkan bahwa bahwa titik-titik cukup menyebar, namun terjadi penumpukan pada beberapa tempat, sehingga cenderung mencerminkan adanya heteroskesdastisitas pada model regresi.

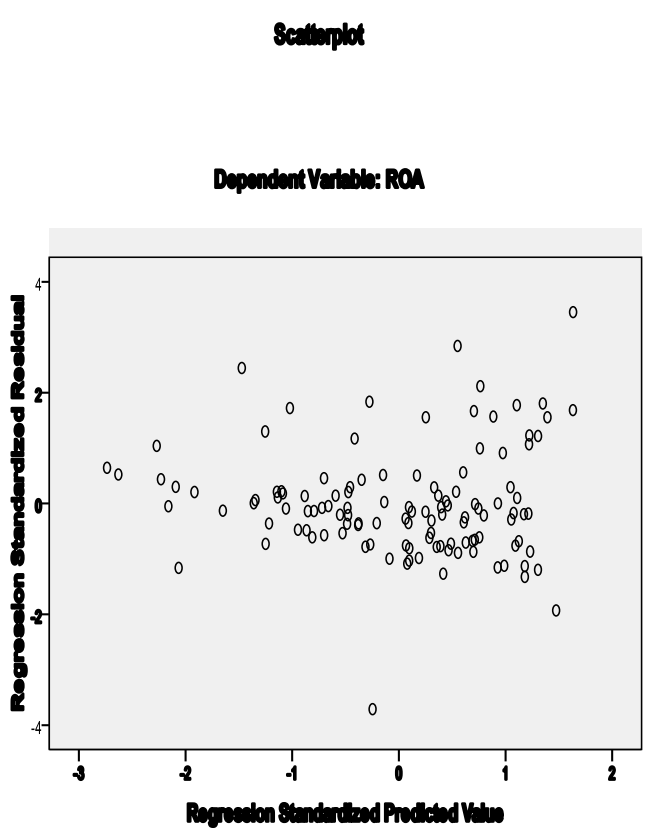

Gambar 3 Hasil Uji Heteroskesdastisitas Sumber : Data Primer Yang diolah (2006-2010)

Selanjutnya, berdasarkan Uji White, terlihat hasilnya signifikan dengan p-value untuk Chi-squared lebih kecil dari 5\% (Tabel 4). Dengan demikian, terbukti adanya permasalahan heteroskedastisitas pada model regresi.(Boyd, 2009)

\section{Tabel 4. Uji Heteroskesdastisitas}

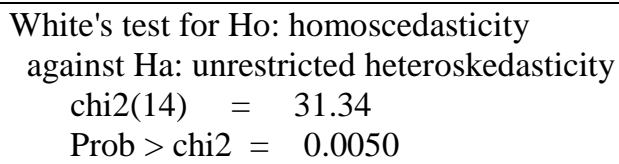

Sumber : Data Primer Yang diolah (2006-2010)

\section{d. Uji Autokorelasi}

Uji Autokorelasi dilakukan dengan memperhatikan hasil nilai Durbin Watson sebagaimana tercantum pada Tabel berikut:

\section{Tabel 5 Uji Autokorelasi}

\begin{tabular}{lrrrrr}
\multicolumn{8}{c}{ Model Summary } \\
\hline Nodel & $R$ & R Square & $\begin{array}{c}\text { Adjusted R } \\
\text { Square }\end{array}$ & $\begin{array}{c}\text { Std. Error of } \\
\text { the Estimate }\end{array}$ & $\begin{array}{c}\text { Durbin- } \\
\text { Watson }\end{array}$ \\
\hline 1 & $.478^{8}$ & .229 & .202 & .31080 & .727 \\
\hline a. Predictors: (Constant), LNTA, LNJASALAN, LNTRANSVAL, LNPROWKOM \\
b. DependentVariable: ROA
\end{tabular}

Sumber : Data Primer Yang diolah (2006-2010)

Tabel 5. memperlihatkan bahwa nilai Durbin Watson sebesar 0,727 atau menjauhi angka 2, sehingga dapat dikatakan terjadi autokorelasi 


\section{Pengujian Hipotesis}

\section{a. Uji-T Test}

Dalam melakukan uji $\mathrm{t}$ ini digunakan hasil regresi berganda. Mengingat dari uji klasik ditemukan adanya permasalahan autokorelasi dan heteroskesdastisitas, maka untuk solusinya digunakan Newey West (1987) standard error

Tabel 6. Hasil Regresi Berganda

Regression with Newey-West standard errors Number of obs $=120$

maximum lag: $1 \mathrm{~F}(4,115)=5.83$

Prob $>\mathrm{F} \quad=0.0003$

Newey-West

roa Coef Std.Err t $\mathrm{P}>|\mathrm{t}| \quad$ [95\% Conf. Interval]

lnprovko $.0714139 \quad 0301614 \quad 2.37 \quad 0.020 \quad 0116699$ .1311578

\begin{tabular}{ccccccc} 
Intransval| & .0445761 & .02104 & 2.12 & 0.036 \\
.0028999 & .0862524 & & & & \\
lnjasalain & .0719823 & .0233354 & 3.08 & 0.003 \\
.0257593 & .1182053 & & & & & \\
Inta | & .0240646 & .0284284 & -0.85 & 0.399 & - \\
.0803759 & .0322466 & & & & \\
cons | & .3887462 & .3828674 & 1.02 & 0.312 & - \\
.3696404 & 1.147133 & & & & \\
\hline
\end{tabular}

Catatan: $\mathrm{Lag}=1$ dihitung dengan rumus $\mathrm{T}^{\wedge} 0,25$.

Sumber : Data Primer Yang diolah (2006-2010)

Penelitian ini menggunakan tingkat signifikan $(\alpha)$ sebesar 5\% serta derajat kebebasan sebesar 115, sehingga t-tabel yang akan digunakan sebagai nilai kritis untuk menerima atau menolak hipotesis adalah sebesar $-1,980$ dan 1,980 .

Berikut adalah Uji-t untuk masing-masing variabel bebas:

1. Pendapatan Provisi dan Komisi (LNPROVKOM) dengan t-hitung sebesar 2,37 dan p-value sebesar 0,020. Karena t-hitung > dari t-tabel dan $\mathrm{p}$-value $<5 \%$, maka dapat diartikan bahwa pengaruh variable ini terhadap ROA adalah signifikan. Dengan demikian, Hipotesis 1 yang tercantum di Bab II memperoleh dukungan atau terbukti. Dalam hal ini, semakin tinggi Pendapatan Provisi dan Komisi (LNPROVKOM), akan semakin tinggi pula ROA bank.

2. Pendapatan Transaksi Valuta Asing (LNTRANSVAL) dengan t-hitung sebesar 2,12 dan p-value sebesar 0,036. Karena t-hitung > dari t-tabel dan $\mathrm{p}$-value $<5 \%$, maka dapat diartikan bahwa pengaruh variable ini terhadap ROA adalah signifikan. Dengan demikian, Hipotesis 2 yang tercantum di Bab II memperoleh dukungan atau terbukti. Dalam hal ini, semakin tinggi Pendapatan Transaksi Valas (LNTRANSVAL), akan semakin tinggi pula ROA bank.
3. Pendapatan Jasa Perbankan Lainnya (LNJASALAIN) dengan t-hitung sebesar 3,08 dan p-value sebesar 0,003. Karena t-hitung > dari t-tabel dan $\mathrm{p}$-value $<5 \%$, maka dapat diartikan bahwa pengaruh variable ini terhadap ROA adalah signifikan. Dengan demikian, Hipotesis 3 yang tercantum di $\mathrm{Bab}$ II memperoleh dukungan atau terbukti. Dalam hal ini, semakin tinggi Pendapatan Jasa Perbankan Lainnya (LNJASALAIN), akan semakin tinggi pula ROA bank.

4. Total Asset (TA) dengan t-hitung sebesar -0,85 dan p-value sebesar 0,399. Karena t-hitung < dari t-tabel dan p-value > 5\%, maka dapat diartikan bahwa pengaruh variable ini terhadap ROA adalah tidak signifikan. Dengan demikian, Hipotesis 4 yang tercantum di Bab II tidak memperoleh dukungan atau tidak terbukti.

\section{b. Uji-F}

Hasil Uji F disajikan pada Tabel berikutnya. Hasil Uji ini menunjukkan bahwa variabel bebas secara bersama-sama berpengaruh terhadap variabel terikat jika p-value lebih kecil dari level of significant yang ditentukan (dalam hal ini 5\%), atau F-hitung lebih besar dari F-tabel. F tabel dihitung dengan cara df1 $=\mathrm{k}-1$, dan $\mathrm{df} 2=\mathrm{n}-\mathrm{k}$, $\mathrm{k}$ adalah jumlah variabel terikat dan variabel bebas.

Tabel 7. Hasil Uji F

$$
\begin{array}{rlc}
\text { Number of obs } & = & 120 \\
F(4,115) & = & 5.83 \\
\text { Prob }>F & = & 0.0003
\end{array}
$$

\section{Sumber : Data Primer Yang diolah (2006-2010)}

Dari Tabel 7 diketahui bahwa F-hitung adalah sebesar 5,83 sedangkan F-tabel $\left(\mathrm{F}_{5 \%} \cdot 4,115\right)=2,45$. Sementara p-value adalah 0,0003 . Dengan demikian F-hitung lebih besar dari F-tabel dan p-value lebih kecil dari 5\%. Artinya variabel bebas secara bersama-sama berpengaruh signifikan terhadap variabel terikat.

\section{Koefisien Determinasi $\left(\mathbf{R}^{\mathbf{2}}\right)$}

Hasil perhitungan Koefisien Determinasi $\left(\mathrm{R}^{2}\right)$ disajikan pada Tabel berikut ini.

Tabel 8 Koefisien Determinasi $\left(\mathbf{R}^{2}\right)$ Model Summary

\begin{tabular}{lcrrrr}
\hline Model & $R$ & R Square & $\begin{array}{c}\text { Adjusted R } \\
\text { Square }\end{array}$ & $\begin{array}{c}\text { Std. Error of } \\
\text { the Estimate }\end{array}$ & $\begin{array}{c}\text { Durbin- } \\
\text { Watson }\end{array}$ \\
\hline 1 & $.478^{\mathrm{a}}$ & .229 & .202 & .31080 & .727 \\
\hline a. Predictors: (Constant), LNTA, LNJASALAN, LNTRANSVAL, LNPROWKOM \\
b. Dependent Variable: ROA
\end{tabular}

Sumber : Data Primer Yang diolah (2006-2010) 
Tabel 8 menunjukkan bahwa nilai koefisien determinasi yang sudah disesuaikan (Adjusted $R^{2}$ ) sebesar 0,202. Artinya 20,20\% variasi pada variabel terikat ROA dijelaskan oleh variasi pada seluruh variabel bebas. Sedangkan sisanya $79,80 \%$ dijelaskan oleh variasi pada variabel lain diluar model penelitian.

\section{KESIMPULAN}

Penelitian ini mencoba untuk mengkaji pengaruh fee based income terhadap ROA dari bank-bank yang terdaftar di Bursa Efek Indonesia periode 20062010. Berdasarkan hasil uji hipotesis yang telah dilakukan diperoleh kesimpulan sebagai berikut:

1. Semua variable bebas yang mencerminkan kegiatan fee based income (pendapatan provisi dan komisi, pendapatan transaksi valuta asing dan pendapatan jasa perbankan lainnya) secara individual berpengaruh positif dan signifikan terhadap ROA.

2. Total Asset secara individual tidak berpengaruh signifikan terhadap ROA.

3. Secara simultan (bersama-sama), seluruh variabel bebas (pendapatan provisi dan komisi, pendapatan transaksi valuta asing, pendapatan jasa perbankan lainnya dan total assets) berpengaruh signifikan terhadap ROA.

4. Sekitar $20,20 \%$ variasi pada variabel terikat ROA dijelaskan oleh variasi pada seluruh variabel bebas

\section{REFERENSI}

Boyd, D. (2009). Heteroskesdasticity. London: University of East.

Kasmir. (2002). Bank dan Lembaga Keuangan Lainnya. Jakarta: PT Raja Grafindo Persada.

Nugroho, B. A. (2005). Strategi Jitu Memilih Metode Statistik Penelitian dengan SPSS. Semarang.: Andi.

S. Munawir. (2004). Analisis Laporan Keuangan (4th ed.). Yogyakarta.: Liberty.

Umar. (2005). No Title. Jakarta: Rajawali Pers.

Arief Fadholi, Lulus dari Program PascaSarjana Universitas Trisakti tahun 2011. Dosen pada program studi Sistem Informasi Akunatnsi Universitas Bina Sarana Informatika Jakarta. 